\title{
The posited effect of positive affect in anorexia nervosa: Advocating for a forgotten piece of a puzzling disease
}

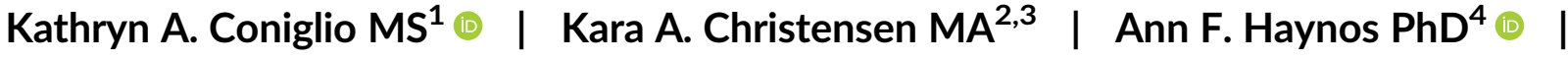 \\ Renee D. Rienecke PhD ${ }^{2,5,6}$ @ | Edward A. Selby PhD ${ }^{1}$
}

\author{
${ }^{1}$ Department of Psychology, Rutgers, The \\ State University of New Jersey, Piscataway, \\ New Jersey \\ ${ }^{2}$ Department of Psychiatry and Behavioral \\ Sciences, Medical University of South Carolina, \\ Charleston, South Carolina \\ ${ }^{3}$ Department of Psychology, The Ohio State \\ University, Columbus, Ohio \\ ${ }^{4}$ Department of Psychiatry, University of \\ Minnesota, Minneapolis, Minnesota \\ ${ }^{5}$ Department of Pediatrics, Medical University \\ of South Carolina, Charleston, South Carolina \\ ${ }^{6}$ Department of Psychiatry, University of \\ Michigan, Ann Arbor, Michigan

\section{Correspondence} \\ Edward A. Selby, Department of Psychology, \\ Rutgers, The State University of New Jersey, \\ Piscataway, NJ. \\ Email: eas268@psych.rutgers.edu \\ Funding information \\ National Institute of Mental Health, Grant/ \\ Award Number: K23MH112867; National \\ Science Foundation, Grant/Award Number: \\ DGE-1433187
}

\begin{abstract}
Anorexia nervosa (AN) is a complex and life-threatening eating disorder. Current models of AN onset and maintenance have largely focused on the role of negative affect, while fewer models have described the role of positive affect (PA). Given that these theoretical models have informed current treatment approaches, and that treatment remains minimally effective for adults with $\mathrm{AN}$, we advocate that targeting PA is one avenue for advancing maintenance models and by extension, treatment. We specifically propose that $A N$ may arise and be chronically and pervasively maintained as a function of dysregulated PA in response to weight loss and weight loss behaviors (e.g., restriction, excessive exercise), to a degree that is not accounted for in existing models of AN. We present evidence from multiple domains, including biological, behavioral, and self-report, supporting the hypothesis that PA dysregulation in AN contributes to the maintenance of the disorder. We conclude with several specific avenues for treatment development research as well as a call for future work elucidating the biological correlates of PA.
\end{abstract}

\section{KEYWORDS}

anorexia nervosa, positive affect, positive affect dysregulation

\section{1 | INTRODUCTION}

Anorexia nervosa (AN) is a severe disorder for which no gold-standard treatment exists for adults (Watson \& Bulik, 2013; Zipfel, Giel, Bulik, Hay, \& Schmidt, 2015). A growing body of work has conceptualized AN as a disorder of emotion dysregulation (e.g., Haynos \& Fruzzetti, 2011). While the evidence for the role of negative affect (NA) in predicting engagement in eating disorder behaviors is growing (Haynos et al., 2017), we concurrently propose that the role of positive affect (PA) in the onset and maintenance of $\mathrm{AN}$ is comparatively far less prioritized and incorporated into etiological theories of $A N$ or treatment development efforts for AN. Some early theories of AN have credited PA from weight loss as critical to the onset of the disorder (e.g., Slade, 1982), but have been eclipsed by more recent theories that have posited that cognitive (Fairburn, Cooper, \& Shafran, 2003) or behavioral (Walsh, 2013) mechanisms are central to the disorder (Table 1). There is a vital need to reinvigorate empirical inquiries into conceptualizations of PA as a trigger for, and reinforcer of, AN to improve the specificity and efficacy of treatment.

In this article, we summarize the limited, but promising, literature on PA in AN from behavioral, psychological, and biological perspectives to explain how this process may contribute to the onset and maintenance of AN. The purpose of putting forth this idea is to highlight the questions that remain unanswered despite what these prior important theories have contributed to our understanding of AN. This holds great contemporary relevance given the advent of novel, advanced methods that have greatly improved the specificity with which affect is studied. Therefore, we wish to clarify, expand, and encourage the study of PA in AN in light of the new evidence and technologies to study PA with the goal of improving interventions. 
TAB LE 1 Previous theories and treatments targeting positive affect in anorexia nervosa

\begin{tabular}{|c|c|c|c|c|}
\hline \multirow[b]{2}{*}{ Theory } & \multirow[b]{2}{*}{ Description } & \multirow[b]{2}{*}{ Role of positive affect (PA) } & \multicolumn{2}{|c|}{$\begin{array}{l}\text { PA implicated as } \\
\text { primary factor in AN }\end{array}$} \\
\hline & & & Onset & Maintenance \\
\hline $\begin{array}{l}\text { Vitousek and } \\
\text { Hollon (1990) }\end{array}$ & $\begin{array}{l}\text { Anorexia nervosa features strongly entrenched } \\
\text { weight-related beliefs about the self (i.e., } \\
\text { self-schemas) such that weight is closely tied } \\
\text { to personal value and worth }\end{array}$ & $\begin{array}{l}\text { Emphasizes cognitions over affect in explaining } \\
\text { the maintenance of AN, describes those with } \\
\text { AN as being "moralistic individuals" able to } \\
\text { exert self-control, implying the experience of } \\
\text { positive affect is scant, possibly even avoided }\end{array}$ & No & No \\
\hline $\begin{array}{l}\text { Fairburn et al. } \\
\text { (2003) }\end{array}$ & $\begin{array}{l}\text { Anorexia nervosa is maintained by an } \\
\text { over-evaluation of one's shape and weight } \\
\text { (and being able to control them) }\end{array}$ & $\begin{array}{l}\text { Emphasizes cognitions over affect such that } \\
\text { diversifying means by which one evaluates } \\
\text { him/herself reduces food restriction. Mood } \\
\text { intolerance (typically intolerance of negative } \\
\text { affect) gives rise to binge eating and purging } \\
\text { behaviors }\end{array}$ & No & No \\
\hline $\begin{array}{l}\text { Schmidt and } \\
\text { Treasure } \\
\text { (2006) }\end{array}$ & $\begin{array}{l}\text { Anorexia nervosa is maintained by a cognitively } \\
\text { rigid thinking style, avoidance of negative } \\
\text { emotions, pro-anorexia beliefs, and both } \\
\text { positive and negative responses from others } \\
\text { regarding the physical appearance of the } \\
\text { person with the disorder }\end{array}$ & $\begin{array}{l}\text { Initially, restraint is maintained intra-personally } \\
\text { by positive reinforcement from temporary } \\
\text { mood improvement. Pro-anorexia beliefs and } \\
\text { positive responses from others also elicit PA }\end{array}$ & Yes & $\mathrm{No}^{\mathrm{a}}$ \\
\hline Walsh (2013) & $\begin{array}{l}\text { Anorexia nervosa is initially maintained through } \\
\text { positive reinforcement of weight loss, and is } \\
\text { subsequently maintained through habitual } \\
\text { food restriction that persists regardless of } \\
\text { weight loss }\end{array}$ & $\begin{array}{l}\text { Dieting behavior is positively reinforced } \\
\text { through successful weight loss and } \\
\text { negatively reinforced through successfully } \\
\text { alleviating negative affect. Eventually, dieting } \\
\text { persists regardless of presence or absence of } \\
\text { PA from weight loss }\end{array}$ & Yes & No \\
\hline
\end{tabular}

Abbreviations: AN, anorexia nervosa; PA, positive affect.

${ }^{\mathrm{a}}$ The role of positive affect in disorder maintenance is acknowledged but not as primary.

\section{2 | TOO MUCH OF A GOOD THING?}

PA dysregulation can involve PA experienced in nonadaptive contexts or to an inappropriate degree, which can prompt engagement in a range of risky and disordered behaviors (Gruber, Mauss, \& Tamir, 2011). The idea that PA is not an unconditionally beneficial mood state has gained traction in the study of other psychological disorders (e.g., bipolar disorder; Gruber, 2011), but has yet to be applied in the eating disorders field.

The dysregulated PA of relevance to AN appears to be characterized by inappropriate, disorder-congruent PA (e.g., consumption of proana stimuli), which may ultimately positively reinforce weight loss behaviors. Although there are ongoing debates about whether positive and negative reinforcement represent distinct mechanisms (Barberini, Morrison, Saez, Lau, \& Salzman, 2012), there is preliminary evidence in AN that PA and NA mechanisms may operate both independently and jointly, thereby simultaneously positively and negatively reinforcing weight loss behaviors (Selby et al., 2015). Importantly, this dysregulated PA is distinct from anhedonia (i.e., diminished/blunted positive affective experience), on which the majority of research on PA in AN has focused
(Kaye, Wierenga, Bailer, Simmons, \& Bischoff-Grethe, 2013). To date, minimal research has examined the degree to which PA may be inappropriately or excessively generated either by eating disorder behaviors (e.g., restriction, compulsive exercise) and/or by environmental cues that reinforce weight loss.

PA dysregulation is a relevant area for study in light of qualitative accounts that suggest that many with AN experience high levels of PA in response to weight loss both before and after AN onset (Nordbø, Espeset, Gulliksen, Skårderud, \& Holte, 2006). Individuals with AN also report receiving desirable social responses to weight loss behaviors (Nordbø et al., 2006), such as restriction or over-exercising, suggesting another pathway to positive reinforcement. Although the habit model of AN (Walsh, 2013), which characterizes food restriction as a persistent habitual behavior that occurs outside conscious choice, credits PA as a mechanism of the disorder in its early onset stages due to weight loss success and interpersonal reinforcement, it posits that habit formation replaces PA as the primary maintaining mechanism of restriction over time. Other models suggest insufficient PA (e.g., anhedonia) as a potential mechanism promoting symptoms of AN (Kaye et al., 2013), but have yet to explore dysregulated PA in response to eating disorder 
behaviors. We propose that PA may influence the onset of $A N$ as the habit model suggests, and also may be chronically maintained by elevated PA in response to disordered eating, to a degree that is not accounted for in existing models.

\section{3 | CURRENT EVIDENCE}

There is evidence from multiple domains suggesting that PA dysregulation in AN leads to both onset and maintenance of the disorder:

\section{1 | Self-report}

Whereas individuals with $\mathrm{AN}$ often report lower baseline reward responsivity on temperamental measures (Vervaet, Van Heeringen, \& Audenaert, 2004), they report more positive affective reactions to low-calorie foods, low-weight bodies, and physical activity cues (Cowdrey, Finlayson, \& Park, 2013; Fladung et al., 2010; Giel et al., 2013), suggesting that these cues may be among the few to generate PA. This is further corroborated by ecological momentary assessment (EMA) research that measures affect and behaviors in real-time. One EMA study found that diminished ability to distinguish across positive affective states led to PA dysregulation, which motivated and reinforced weight loss behaviors (Selby et al., 2014). Further, daily PA lability has been associated with greater weight loss behaviors, selfweighing, and body-checking among individuals with AN (Selby et al., 2015). Momentary analyses of the same data found elevated PA during and after restrictive eating episodes, compared to normal meals (Fitzsimmons-Craft et al., 2015), and that restrictive eating resulted in increased self-assurance among those with restricting subtype (Haynos et al., 2017). Finally, lower PA preceded days for which restrictive eating was more likely (Engel et al., 2013), lending further evidence that restrictive eating may be utilized to momentarily enhance reward experiencing.

\section{2 | Behavioral}

Studies have demonstrated that underweight and physical activity cues may elicit PA to a greater extent than monetary incentives in this population. In one study, individuals with AN sacrificed more money in a behavioral task to view bodies that were thinner (Watson, Werling, Zucker, \& Platt, 2010). Similarly, on progressive ratio tasks, individuals with $\mathrm{AN}$ sacrificed more money and exerted more effort to engage in physical activity compared to control participants (Klein et al., 2010). These results indicate the high salience and behavioral drive for such AN-relevant cues.

\section{3 | Biological}

Individuals with AN demonstrate elevated skin conductance, decreased eye blink startle, and increased electroencephalogram late positive potential in response to underweight stimuli (Clarke, Ramoz, Fladung, \& Gorwood, 2016; Horndasch et al., 2018; O'Hara et al.,
2016), indicating greater salience and PA responding. This altered dopaminergic functioning and reward response is corroborated by a study showing increased eye blink startle in response to thinness images following dopamine depletion (O'Hara et al., 2016).

There is also evidence of disturbance in the structural and functional organization of reward neural circuitry, as well as the dopaminergic system in AN (Kaye et al., 2013), which may make these individuals vulnerable to PA dysregulation. AN involves heightened activation in key regions of reward circuitry (e.g., striatum) in response to low calorie foods and underweight bodies (Fladung et al., 2010; Foerde, Steinglass, Shohamy, \& Walsh, 2015), further suggesting that restrictive eating and weight loss induce PA. Several studies have also detected abnormal neural responding in reward regions to palatable food cues; however, the direction of these findings is inconsistent, with some finding enhanced (Frank, Shott, Hagman, \& Mittal, 2013), and others decreased (Brooks et al., 2011) reward responding compared to controls.

\section{4 | CALL TO ACTION: OUR IDEA WORTH RESEARCHING}

Several gaps remain in our knowledge of how PA contributes to the onset and maintenance of AN. Thus, we offer the following suggestions to the field for advancing research with respect to theoretical models, assessment, and treatment:

\section{1 | Operationalizing PA}

It may be that those with $\mathrm{AN}$ have pervasive difficulty experiencing $\mathrm{PA}$ in general, and therefore need to engage in extreme, disordersyntonic behaviors to elicit PA. Alternatively, those with AN may experience difficulty keeping pervasive NA at bay, and up-regulate PA to do so. Because there is mixed evidence as to whether PA and NA are orthogonal (Diener \& Emmons, 1984) or represent two ends of a bipolar spectrum (Russell \& Carroll, 1999), further research is needed to address this issue. A third possibility is that individuals with $A N$ may exhibit intact PA regulation at the onset of the disorder, but become over-conditioned to derive an excess of PA from stimuli associated with weight loss as the disorder progresses, akin to the incentive salience hypothesis of drug addiction (Robinson \& Berridge, 1993). More research is needed to test these alternate theories to inform more precise and comprehensive mechanistic models.

\subsection{Assessment and methods}

\subsection{1 | Longitudinal research}

Although dysregulated PA may contribute to disordered eating behaviors, there is also evidence that increasing nondisorder specific PA is beneficial for treatment outcomes (Cardi, Esposito, Clarke, Schifano, \& Treasure, 2015), indicating that PA may switch during the illness course from hindering to helping recovery. Longitudinal studies are essential to contextualize these findings and to understand the extent 
TAB LE 2 Treatment interventions to target dysregulated positive affect in anorexia nervosa

\begin{tabular}{|c|c|}
\hline Technique & Evidence base \\
\hline $\begin{array}{l}\text { Improve detection and labeling } \\
\text { of positive emotions to } \\
\text { counter low positive } \\
\text { emotion differentiation }\end{array}$ & $\begin{array}{l}\text { Mindfulness module in } \\
\text { dialectical behavior therapy } \\
\text { (Linehan, 1993, 2015) }\end{array}$ \\
\hline $\begin{array}{l}\text { Explore and challenge core } \\
\text { beliefs underlying stated } \\
\text { pro-anorexia beliefs }\end{array}$ & $\begin{array}{l}\text { Maudsley model of anorexia } \\
\text { nervosa treatment for adults } \\
\text { (MANTRA) (Schmidt \& } \\
\text { Treasure, 2006; Schmidt, } \\
\text { Wade, \& Treasure, 2014) }\end{array}$ \\
\hline $\begin{array}{l}\text { Encourage shift in balance } \\
\text { between perceived benefits } \\
\text { and drawbacks of the } \\
\text { disorder in favor of the } \\
\text { latter to elicit change talk } \\
\text { and treatment adherence }\end{array}$ & $\begin{array}{l}\text { Motivational interviewing } \\
\text { (Miller \& Rollnick, 2002) }\end{array}$ \\
\hline $\begin{array}{l}\text { Promote engagement in } \\
\text { nondisorder-related } \\
\text { activities that elicit positive } \\
\text { emotion }\end{array}$ & $\begin{array}{l}\text { Emotion regulation module in } \\
\text { dialectical behavior therapy } \\
\text { (Linehan, 1993, 2015) } \\
\text { Behavioral activation for } \\
\text { depression (Jacobson, 2001) } \\
\text { Values clarification and } \\
\text { committed action } \\
\text { acceptance and } \\
\text { commitment therapy } \\
\text { (Hayes, Strosahl, \& Wilson, } \\
\text { 2011) }\end{array}$ \\
\hline $\begin{array}{l}\text { Self-monitoring: } \\
\text { - Self-monitor positive affect } \\
\text { in vivo in conjunction with } \\
\text { self-monitoring of eating } \\
\text { disorder behaviors to track } \\
\text { their relationship over time } \\
\text { - Self-monitor use of, and } \\
\text { efficacy of, skills to reduce, } \\
\text { redirect, or tolerate } \\
\text { (without acting on) } \\
\text { inappropriate positive } \\
\text { affect }\end{array}$ & $\begin{array}{l}\text { Self-monitoring, as is used in } \\
\text { cognitive behavioral therapy } \\
\text { for eating disorders } \\
\text { (Fairburn, 2008) } \\
\text { Diary card, as is used in } \\
\text { dialectical behavior therapy } \\
\text { (Linehan, 1993) }\end{array}$ \\
\hline $\begin{array}{l}\text { Moderate social media } \\
\text { exposure by limiting positive } \\
\text { affect-inducing, } \\
\text { disorder-promoting content } \\
\text { while increasing exposure to } \\
\text { positive affect-inducing, } \\
\text { disorder-discouraging } \\
\text { content }\end{array}$ & $\begin{array}{l}\text { Stimulus control (Steinglass } \\
\text { et al., 2018) }\end{array}$ \\
\hline $\begin{array}{l}\text { Develop effective responses } \\
\text { to interpersonal comments } \\
\text { (even positive comments) } \\
\text { about weight and shape }\end{array}$ & $\begin{array}{l}\text { Interpersonal therapy (Wilfley } \\
\text { et al., 1993) } \\
\text { Interpersonal effectiveness } \\
\text { module in dialectical } \\
\text { behavior therapy (Linehan, } \\
\text { 1993) }\end{array}$ \\
\hline $\begin{array}{l}\text { Promote the development of } \\
\text { prosocial positive emotions } \\
\text { (e.g., compassion) instead of } \\
\text { self-focused positive } \\
\text { emotions (e.g., pride) }\end{array}$ & $\begin{array}{l}\text { (Gruber et al., 2011; Selby } \\
\text { et al., 2014) }\end{array}$ \\
\hline
\end{tabular}

(Continues)
TABLE 2 (Continued)

$\begin{array}{lc}\begin{array}{l}\text { Technique } \\ \text { Provide psychoeducation to } \\ \text { family members (i.e., } \\ \text { parents, siblings, partners) to }\end{array} & \begin{array}{c}\text { Evidence base } \\ \text { discourage }\end{array} \\ \begin{array}{l}\text { \& Le Grange, 2013) } \\ \text { praise/comments about } \\ \text { weight loss or body shape, } \\ \text { and to charge the family } \\ \text { members with the task of } \\ \text { educating the patient's } \\ \text { larger social network }\end{array} & \text { nervosa (Bulik, Baucom, } \\ \end{array}$

${ }^{\text {aThis }}$ proposed psychoeducation is not expressly addressed in either treatment.

to which dysregulated PA predates illness onset, and whether the link between PA and eating disorder behavior changes as a function of illness stage.

\subsection{2 | Biological correlates}

Prior research on the biological correlates of appetitive responding has primarily focused on the construct of reward and corresponding brain regions (e.g., striatum). Although it is often assumed that reward is synonymous with PA, few of these studies examine how biological responses in reward-associated neural circuitry or psychophysiological indices correspond with subjective affective experience. Further, it is now widely acknowledged that subjective experiences related to PA are regulated by a broader range of brain structures, including some areas that overlap with the processing of NA (Suardi, Sotgiu, Costa, Cauda, \& Rusconi, 2016), further suggesting the need for multimethod studies in this area. Additionally, although most prior studies investigating the neurobiology of reward in AN have isolated specific brain regions, novel MRI methods have led to increased interest in measuring structural and functional connectivity to examine how neural circuits function in correspondence. In addition, many prior studies have examined biological responses to passive stimuli, such as pictures of food or underweight bodies, which may not translate directly to engagement in eating disorder behaviors. Therefore, examination of the biological correlates of PA during active decision-making (e.g., food choice; Foerde et al., 2015), perhaps utilizing emerging computational models (Huys \& Renz, 2017), may yield more robust and generalizable results. Recent advances in magnetic resonance and computational analysis make this a particularly opportune time to expand the investigation of PA.

\subsection{3 | Novel methods}

Other new technologies to pioneer PA research in AN may enhance the external validity of PA. Such methods could include: advanced ambulatory assessment with smart watches and continuous physiological monitoring, integration of computerized reward assessment tasks (e.g., delay discounting tailored to weight loss), and virtual reality to simulate positive interpersonal comments about weight. 


\section{3 | Treatment development}

An important question in AN treatment outcome research is whether treatments remain largely ineffective because they fail to act on correctly identified maintenance mechanisms, or whether the mechanisms themselves are incorrectly identified (Jansen, 2016). Although some theories have acknowledged that PA is involved in AN (Table 1), existing treatments fall short of expressly targeting dysregulated PA in AN. For instance, while cognitive-behavioral therapy targets overevaluation of shape and weight (Fairburn, 2008), which may increase self-esteem by diversifying self-evaluative domains, dysregulated PA is not expressly targeted. The ultimate goal of this proposal is to encourage the development of treatments that more specifically target potentially relevant treatment mechanisms, thereby leading to better treatment outcomes, which are desperately needed in AN. A description of the types of treatment interventions that may be relevant to shape PA in AN is provided in Table 2.

\section{5 | CONCLUSION}

We propose that the role of PA in the onset and maintenance of $A N$ is underappreciated and understudied. Dysregulated PA in response to weight loss may contribute to the extreme downward trajectory in weight status characteristic of this disorder. Our idea worth researching calls on the field to understand more clearly the effect of $\mathrm{PA}$ in $\mathrm{AN}$ to improve disorder prognosis.

\section{ACKNOWLEDGMENTS}

Kathryn Coniglio is supported by the National Science Foundation Graduate Research Fellowship Program under DGE-1433187, and Ann Haynos is supported by the National Institute of Mental Health under award number $\mathrm{K} 23 \mathrm{MH} 112867$. The content is solely the responsibility of the authors and does not necessarily represent the official views of the National Science Foundation or the National Institutes of Health.

\section{ORCID}

Kathryn A. Coniglio (iD https://orcid.org/0000-0002-8549-2790 Ann F. Haynos (D) https://orcid.org/0000-0002-2548-1731

Renee D. Rienecke (D) https://orcid.org/0000-0003-0423-7403

\section{REFERENCES}

Barberini, C. L., Morrison, S. E., Saez, A., Lau, B., \& Salzman, C. D. (2012) Complexity and competition in appetitive and aversive neural circuits. Frontiers in Neuroscience, 6, 170. https://doi.org/10.3389/fnins.2012. 00170

Brooks, S. J., ODaly, O. G., Uher, R., Friederich, H. C., Giampietro, V., Brammer, M., ... Campbell, I. C. (2011). Differential neural responses to food images in women with bulimia versus anorexia nervosa. PLoS One, 6, e22259. https://doi.org/10.1371/journal.pone.0022259
Bulik, C. M., Baucom, D. H., Kirby, J. S., \& Pisetsky, E. (2011). Uniting couples (in the treatment of) anorexia nervosa (UCAN). International Journal of Eating Disorders, 44, 19-28. https://doi.org/10.1002/eat.20790

Cardi, V., Esposito, M., Clarke, A., Schifano, S., \& Treasure, J. (2015). The impact of induced positive mood on symptomatic behaviour in eating disorders. An experimental, AB/BA crossover design testing a multimodal presentation during a test-meal. Appetite, 87, 192-198. https:// doi.org/10.1016/j.appet.2014.12.224

Clarke, J., Ramoz, N., Fladung, A.-K., \& Gorwood, P. (2016). Higher reward value of starvation imagery in anorexia nervosa and association with the Val66Met BDNF polymorphism. Translational Psychiatry, 6(6), e829. https://doi.org/10.1038/tp.2016.98

Cowdrey, F. A., Finlayson, G., \& Park, R. J. (2013). Liking compared with wanting for high- and low-calorie foods in anorexia nervosa: Aberrant food reward even after weight restoration1-3. American Journal of Clinical Nutrition, 97, 463-470. https://doi.org/10.3945/ajcn.112. 046011

Diener, E., \& Emmons, R. A. (1984). The independence of positive and negative affect. Journal of Personality and Social Psychology, 47, 1105-1117. https://doi.org/10.1037/0022-3514.47.5.1105

Engel, S. G., Wonderlich, S. A., Crosby, R. D., Mitchell, J. E., Crow, S., Peterson, C. B., ... Gordon, K. H. (2013). The role of affect in the maintenance of anorexia nervosa: Evidence from a naturalistic assessment of momentary behaviors and emotion. Journal of Abnormal Psychology, 122(3), 709-719. https://doi.org/10.1037/a0034010

Fairburn, C. G. (2008). Cognitive behavior therapy and eating disorders. Chichester, England: The Guilford Press.

Fairburn, C. G., Cooper, Z., \& Shafran, R. (2003). Cognitive behaviour therapy for eating disorders: A "transdiagnostic" theory and treatment. Behaviour Research and Therapy, 41, 509-528. https://doi.org/10. 1016/S0005-7967(02)00088-8

Fitzsimmons-Craft, E. E., Accurso, E. C., Ciao, A. C., Crosby, R. D., Cao, L., Pisetsky, E. M., ... Wonderlich, S. A. (2015). Restrictive eating in anorexia nervosa: Examining maintenance and consequences in the natural environment. International Journal of Eating Disorders, 48, 923-931. https://doi.org/10.1002/eat.22439

Fladung, A. K., Grön, G., Grammer, K., Herrnberger, B., Schilly, E., Grasteit, S., ... Von Wietersheim, J. (2010). A neural signature of anorexia nervosa in the ventral striatal reward system. American Journal of Psychiatry, 167, 206-212. https://doi.org/10.1176/appi.ajp. 2009.09010071

Foerde, K., Steinglass, J. E., Shohamy, D., \& Walsh, B. T. (2015). Neural mechanisms supporting maladaptive food choices in anorexia nervosa. Nature Neuroscience, 18, 1571-1573. https://doi.org/10.1038/nn. 4136

Frank, G. K., Shott, M. E., Hagman, J. O., \& Mittal, V. A. (2013). Alterations in brain structures related to taste reward circuitry in ill and recovered anorexia nervosa and in bulimia nervosa. American Journal of Psychiatry, 170, 1152-1160. https://doi.org/10.1176/appi.ajp.2013.12101294

Giel, K. E., Kullmann, S., PreißI, H., Bischoff, S. C., Thiel, A., Schmidt, U., ... Teufel, M. (2013). Understanding the reward system functioning in anorexia nervosa: Crucial role of physical activity. Biological Psychology, 94, 575-581. https://doi.org/10.1016/j.biopsycho.2013.10.004

Gruber, J. (2011). Can feeling too good be bad? Positive emotion persistence (PEP) in bipolar disorder. Current Directions in Psychological Science, 20, 217-221. https://doi.org/10.1177/0963721411414632

Gruber, J., Mauss, I. B., \& Tamir, M. (2011). A dark side of happiness? How, when, and why happiness is not always good. Perspectives on Psychological Science, 6, 222-233. https://doi.org/10.1177/1745691611406927

Hayes, S. C., Strosahl, K. D., \& Wilson, K. G. (2011). Acceptance and commitment therapy: The process and practice of mindful change (2nd ed.). New York: Guilford Press.

Haynos, A. F., Berg, K. C., Cao, L., Crosby, R. D., Lavender, J. M., Utzinger, L. M., ... Crow, S. J. (2017). Trajectories of higher- and lowerorder dimensions of negative and positive affect relative to restrictive 
eating in anorexia nervosa. Journal of Abnormal Psychology, 126, 495-505. https://doi.org/10.1037/abn0000202

Haynos, A. F., \& Fruzzetti, A. E. (2011). Anorexia nervosa as a disorder of emotion Dysregulation: Evidence and treatment implications. Clinical Psychology: Science and Practice, 18, 183-202. https://doi.org/10. 1111/j.1468-2850.2011.01250.x

Horndasch, S., Kratz, O., Van Doren, J., Graap, H., Kramer, R., Moll, G. H., \& Heinrich, H. (2018). Cue reactivity towards bodies in anorexia nervosa - common and differential effects in adolescents and adults. Psychological Medicine, 48, 508-518. https://doi.org/10.1017/ S0033291717001994

Huys, Q. J. M., \& Renz, D. (2017). A formal valuation framework for emotions and their control. Biological Psychiatry, 82, 413-420. https://doi. org/10.1016/j.biopsych.2017.07.003

Jacobson, N. S. (2001). Behavioral activation treatment for depression: Returning to contextual roots. Clinical Psychology: Science and Practice, 8, 255-270. https://doi.org/10.1093/clipsy/8.3.255

Jansen, A. (2016). Eating disorders need more experimental psychopathology. Behaviour Research and Therapy, 86, 2-10. https://doi.org/10. 1016/j.brat.2016.08.004

Kaye, W. H., Wierenga, C. E., Bailer, U. F., Simmons, A. N., \& BischoffGrethe, A. (2013). Nothing tastes as good as skinny feels: The neurobiology of anorexia nervosa. Trends in Neurosciences, 36, 110-120. https://doi.org/10.1016/j.tins.2013.01.003

Klein, D. A., Schebendach, J. E., Gershkovich, M., Bodell, L. P., Foltinb, R. W., \& Walsh, B. T. (2010). Behavioral assessment of the reinforcing effect of exercise in women with anorexia nervosa: Further paradigm development and data. The International Journal of Eating Disorders, 43(7), 611-618. https://doi.org/10.1002/eat.20758

Linehan, M. M. (1993). Cognitive-behavioral treatment of borderline personality disorder. New York: Guilford Press.

Linehan, M. M. (2015). DBT skills training manual (2nd ed.). NY: Guilford Press. Retrieved from http://ovidsp.ovid.com/ovidweb.cgi?T=JS\& PAGE=reference $\& D=$ psyc11\&NEWS $=N \& A N=2015-05780-000$

Lock, J., \& Le Grange, D. (2013). Treatment manual for anorexia nervosa: A family-based approach (2nd ed.). New York: Guilford Press.

Miller, W. R., \& Rollnick, S. (2002). Motivational interviewing. Preparing people for change (2nd ed.). New York: Guilford Press.

Nordbø, R. H. S., Espeset, E. M. S., Gulliksen, K. S., Skårderud, F., \& Holte, A. (2006). The meaning of self-starvation: Qualitative study of patients' perception of anorexia nervosa. International Journal of Eating Disorders, 39, 556-564. https://doi.org/10.1002/eat.20276

O'Hara, C. B., Keyes, A., Renwick, B., Giel, K. E., Campbell, I. C., \& Schmidt, U. (2016). Evidence that illness-compatible cues are rewarding in women recovered from anorexia nervosa: A study of the effects of dopamine depletion on eye-blink startle responses. PLoS One, 11, e0165104. https://doi.org/10.1371/journal.pone.0165104

O'Hara, C. B., Keyes, A., Renwick, B., Leyton, M., Campbell, I. C., \& Schmidt, U. (2016). The effects of acute dopamine precursor depletion on the reinforcing value of exercise in anorexia nervosa. PLoS One, 11, e0145894. https://doi.org/10.1371/journal.pone.0145894

Robinson, T. E., \& Berridge, K. C. (1993). The neural basis of drug craving: An incentive-sensitization theory of addiction. Brain Research Reviews, 18, 247-291. https://doi.org/10.1016/0165-0173(93)90013-P

Russell, J. A., \& Carroll, J. M. (1999). On the bipolarity of positive and negative affect. Psychological Bulletin, 125, 3-30. https://doi.org/10.1037/ 0033-2909.125.1.3

Schmidt, U., \& Treasure, J. (2006). Anorexia nervosa: Valued and visible. A cognitive-interpersonal maintenance model and its implications for research and practice. British Journal of Clinical Psychology, 45, 343-366. https://doi.org/10.1348/014466505X53902
Schmidt, U., Wade, T. D., \& Treasure, J. (2014). The Maudsley model of anorexia nervosa treatment for adults (MANTRA): Development, key features, and preliminary evidence. Journal of Cognitive Psychotherapy, 28, 48-71. https://doi.org/10.1891/0889-8391.28.1.48

Selby, E. A., Cornelius, T., Fehling, K. B., Kranzler, A., Panza, E. A., Lavender, J. M., ... Le Grange, D. (2015). A perfect storm: Examining the synergistic effects of negative and positive emotional instability on promoting weight loss activities in anorexia nervosa. Frontiers in Psychology, 6(August), 1260. https://doi.org/10.3389/fpsyg.2015.01260

Selby, E. A., Wonderlich, S. A., Crosby, R. D., Engel, S. G., Panza, E., Mitchell, J. E., ... Le Grange, D. (2014). Nothing tastes as good as thin feels: Low positive emotion differentiation and weight-loss activities in anorexia nervosa. Clinical Psychological Science, 2(4), 514-531. https://doi.org/10.1177/2167702613512794

Slade, P. (1982). Towards a functional analysis of anorexia nervosa and bulimia nervosa. British Journal of Clinical Psychology, 21(3), 167-179. https://doi.org/10.1111/j.2044-8260.1982.tb00549.x

Steinglass, J. E., Glasofer, D. R., Walsh, E., Guzman, G., Peterson, C. B., Walsh, B. T., ... Wonderlich, S. A. (2018). Targeting habits in anorexia nervosa: A proof-of-concept randomized trial. Psychological Medicine, 48, 2584-2591. https://doi.org/10.1017/S00332 $9171800020 \mathrm{X}$

Suardi, A., Sotgiu, I., Costa, T., Cauda, F., \& Rusconi, M. (2016). The neural correlates of happiness: A review of PET and $\mathrm{fMRI}$ studies using autobiographical recall methods. Cognitive, Affective, \& Behavioral Neuroscience, 16, 383-392. https://doi.org/10.3758/s13415-016-0414-7

Vervaet, M., Van Heeringen, C., \& Audenaert, K. (2004). Personalityrelated characteristics in restricting versus binging and purging eating disordered patients. Comprehensive Psychiatry, 45, 37-43. https://doi. org/10.1016/j.comppsych.2003.09.008

Vitousek, K. B., \& Hollon, S. D. (1990). The investigation of schematic content and processing in eating disorders. Cognitive Therapy and Research, 14(2), 191-214.

Walsh, B. T. (2013). The enigmatic persistence of anorexia nervosa. American Journal of Psychiatry, 170, 477-484. https://doi.org/10.1176/appi. ajp.2012.12081074

Watson, H. J., \& Bulik, C. M. (2013). Update on the treatment of anorexia nervosa: Review of clinical trials, practice guidelines and emerging interventions. Psychological Medicine, 43, 2477-2500. https://doi.org/ 10.1017/S0033291712002620

Watson, K. K., Werling, D. M., Zucker, N. L., \& Platt, M. L. (2010). Altered social reward and attention in anorexia nervosa. Frontiers in Psychology, 1, 36. https://doi.org/10.3389/fpsyg.2010.00036

Wilfley, D. E., Agras, W. S., Telch, C. F., Rossiter, E. M., Schneider, J. A., Cole, A. G., ... Raeburn, S. D. (1993). Group cognitive-Behavioral therapy and group interpersonal psychotherapy for the nonpurging bulimic individual: A controlled comparison. Journal of Consulting and Clinical Psychology, 61, 296-305. https://doi.org/10.1037/0022-006X.61.2.296

Zipfel, S., Giel, K. E., Bulik, C. M., Hay, P., \& Schmidt, U. (2015). Anorexia nervosa: Aetiology, assessment, and treatment. The Lancet Psychiatry, 2, 1099-1111. https://doi.org/10.1016/S2215-0366(15)00356-9

How to cite this article: Coniglio KA, Christensen KA, Haynos AF, Rienecke RD, Selby EA. The posited effect of positive affect in anorexia nervosa: Advocating for a forgotten piece of a puzzling disease. Int J Eat Disord. 2019;52:971-976. https://doi.org/10.1002/eat.23147 